\title{
A Quantitative Content Analysis of Person-First Language Use in Healthcare Research, Healthcare Practice, and by Support Groups for People with Disabilities
}

\author{
Maxwell Barnish \\ Independent scholar, London, UK \\ Email: maxbarnish@gmail.com
}

Received 23 August 2014; revised 12 September 2014; accepted 20 September 2014

Copyright (C) 2014 by author and Scientific Research Publishing Inc.

This work is licensed under the Creative Commons Attribution International License (CC BY).

http://creativecommons.org/licenses/by/4.0/

(c) (i) Open Access

\section{Abstract}

This article reports the results of an original quantitative linguistic study that investigated patterns of language use referring to people with disabilities in three data source types: written by support groups run for and by people with disabilities, healthcare researchers, and healthcare providers respectively. Quantitative content analysis was used to categorize the language use in a target sentence in each of the 9000 data sources in terms of whether it emphasized the person (person-first language) or the disability (non-person-first language) following published guidelines. Statistical analysis was conducted using appropriate logistic regression models. There was a significant increase in the use of person-first language in healthcare research articles over the time period 1994-2013, although it remained a minority usage. Use of person-first language was significantly higher in documents produced by support groups run by people with disabilities than in documents produced by healthcare researchers and practitioners. This suggests that healthcare researchers and providers may be more likely to refer to people with disabilities in terms that emphasize the disability rather than the person. Further research is required to confirm these patterns and investigate whether there is a disparity between the wishes of people with disabilities and the language behavior of healthcare researchers and practitioners.

\section{Keywords}

Clinical Linguistics, Language Policy, Sociolinguistics, Quantitative Linguistics

\section{Introduction}

“Words can reflect as well as influence the way people think” (United Kingdom Office for Disability Issues, 
undated) about other people and society. Organizations including the United Kingdom Office for Disability Issues (undated), the American Speech-Language Hearing Association (ASHA) (undated), and the Research and Training Center on Independent Living (2013) have all published guidelines advocating the use of language that emphasizes the person rather than the disability that he or she may happen to have. Calling this "person-first language", ASHA (undated), for example, advises that "disabilities are not persons and they do not define persons, so do not replace person-nouns with disability nouns", such as "the aphasic", "stutterers", "the hearing impaired" and "depressed patients". Instead, such guidelines recommend the use of terms of reference that emphasize the person rather than the disability, such as "people with aphasia", "people who stutter", "people with hearing impairment" and "people with depression". ASHA (undated) guidelines recommend that the term "patient" should only be used for people under the care of hospitals. Since the term "patient" appears to be of particular interest when analyzing terminology used to refer to people with disabilities, it can be useful to differentiate between non-person-first (patient) and non-person-first (other) language.

The term "patient" derives from the Latin patī, which meant "to suffer" (Ayto, 2001). In addition to its medical usage, it can refer to the person or entity to whom an action is performed (Crystal, 1985), emphasizing a passive role, and is also a synonym of "calm" and "compliant" (Spooner, 1998). Hadley and Brodwin (1988) argue that the term "patient" implies that people with disabilities are sick and contagious and that they play a relatively passive role in their treatment, which the authors argue is contrary to the underlying philosophical ethos of rehabilitation practice. Shared decision-making has in recent decades gained credence as a model of treatment choice in which both client and practitioner can participate (Charles, Gafni, \& Whelan, 1997). In the context of depression, United Kingdom National Institute for Clinical Excellence (2009) guidelines recommend shared decisionmaking, while Patel and Bakken (2010) found that $98 \%$ of people with depression in their study wanted to play an active role in choosing their treatment. However, in light of the comments made by Hadley and Brodwin (1988), is it possible that this process is being undermined by unhelpful patterns of language use. Blaska (1993), in advocating the use of person-first language, states that "the words or phrases people speak and write plus the order in which they are sequenced greatly affects the images that are formed about individuals with disabilities and the negative or positive impressions that result”. Therefore, linguistic choices can be of great importance.

Despite the evident relevance of research in this area, only three quantitative empirical investigations of the use of person-first language to refer to people with disabilities could be identified in the published healthcare research literature. Moreover, the most recent was published in 1991; all were restricted to a relatively narrow range of journals in the field of rehabilitation and time periods of no longer than one year and methodological frameworks underpinning the analyses were not stated explicitly. La Forge (1991) assessed 55\% of articles as using person-first language when the entire article was considered, which rose to $71 \%$ when only the title was assessed. Boland (1980) assessed 60\% of articles as using person-first language when the entire article was considered. On the other hand, Patterson (1988) assessed only 27\% of articles as using person-first language using the title as the unit of analysis. No published investigations of the use of person-first language in healthcare practice or by support groups run by and for people with disabilities could be identified. Therefore, it is unknown whether there is a disparity between the language behavior of healthcare researchers and providers and the language behavior, and inferred wishes, of communities of people with disabilities.

The current investigation sought to characterize changing patterns of terminology use in healthcare journal articles from a wide range of journals from four different medical specialties over a twenty-year period using an explicitly stated standardized analysis framework. It also sought to assess differences in these usage patterns between documents produced by healthcare researchers, healthcare providers, and support groups run for and by groups of people with disabilities during the time period 2009-2013. It aimed to be fundamentally a linguistic investigation with dual relevance to linguistics and healthcare researchers.

\section{Methods}

This study did not involve the recruitment of human participants and relied solely on publically available data sources. Therefore, no ethical approval was required.

\subsection{Data Sources}

As the primary mechanism for the dissemination of scientific knowledge, peer-reviewed journal articles were selected as the data source to represent language use by healthcare researchers. Five hundred English-language 
original research articles were randomly sampled from the abstracting database PubMed (United States National Library of Medicine, 1996) for each combination of four time periods (1994-1998, 1999-2003, 2004-2008, and 2009-2013) and four medical conditions from different specialties (prostate cancer, celiac disease, depression, and Parkinson's disease). Due to medical confidentiality, it is difficult to obtain data characterizing the routine communication between healthcare providers and clients. However, websites written by the medical profession for the use of their clients can provide valuable insight into the language used by healthcare providers to refer to people with medical conditions. Family medical centers are often people's first point of contact with the medical profession (Allen, Gay, Crebolder, Heyrman, Svab et al., 2002). Therefore, family medical center websites were taken as an indicator of language use by healthcare providers. Five hundred family medical center websites from the UK, USA, and Australia were randomly sampled during the time period 2009-2013 using web searches. Websites of support groups run by and for people with disabilities offer a valuable published and verifiable insight into the self-held identity of communities of people with disabilities, including the terms of reference they choose to use for themselves. Five hundred support group websites from the UK, USA, and Australia were randomly sampled during the time period 2009-2013 using web searches.

\subsection{Analysis Framework}

Quantitative content analysis is a long-established original research method especially in linguistic and communication research and is used to "determine generalizations about an individual, culture, society or nation" (Go, 1984). It seeks to perform original analysis of the linguistic patterning of existing textual data sources and therefore differs from a literature review, which seeks to summarize the contents of existing published data sources. Analysis was conducted following Riffe, Lacy, and Fico (1998). For each of the three data source types, a specific target statement was defined as the relevant content for the purposes of this analysis. According to Riffe, Lacy, and Fico (1998), relevant content should be selected on a case-by-case basis for each data source and should capture the essence of that data source with regard to the language phenomenon being studied. For healthcare journal articles, the target statement was the sentence in the methods section stating how many people with the particular disability were recruited to the study. For family medical centers, the target statement was the information provided for people who were considering using the center for the first time. For support group web sites, the target statement was the organization's mission statement. Within each target statement, the noun phrase referring to people with medical conditions was defined as the target noun phrase, the unit of analysis for this study. Each target noun phrase was coded into one of three categories-person-first, non-person-first (patient) or non-person-first (other term)—as defined in the introduction to this article. Ten percent of content was recoded in order to establish the reliability of the coding process.

\subsection{Statistical Methods}

Statistical analysis was conducted using PASW version 18 software (SPSS Inc., Chicago: IL). The overarching statistical framework used in this study was logistic regression, which offers a means of assessing the impact of continuous or categorical predictor variables on a categorical outcome variable (Field, 2006). When the outcome variable has more than two categories, a modified version called multinomial logistic regression is used (Greene, 2011). In order to assess changing patterns of terminology use in healthcare journal articles over the period 1994-2013, a two-tailed forced entry multinomial logistic regression model was constructed with coding category (person-first, non-person-first (patient), or non-person-first (other)) as the outcome variable and time period and medical condition as predictor variables. In order to compare terminology use between the three data source types during the time period 2009-2013, it was necessary to combine the two non-person-first categories as a result of a zero cell count. A forced entry binary logistic regression model was constructed with coding category as the outcome variable and data source type as the predictor variable. Bonferroni correction (Abdi, 2007) was applied to both statistic models in order to guard against multiple testing bias.

\section{Results}

\subsection{Reliability Assessment}

No discrepancies occurred between the results of first and second coding for the $10 \%$ of content that was re-coded as a reliability assessment. 


\subsection{Descriptive Statistics}

Descriptive statistics for terminology use in healthcare journals over the period 1994-2013 (see Table 1 and Figure 1) show that "patient" was the term used to refer to participants with disabilities in $68.50 \%$ of articles analyzed. Person-first language was used in $19.50 \%$ of articles analyzed. $13.50 \%$ of articles from the time period 1994-1998 used person-first language compared to 25.80\% of studied articles published between 2009 and 2013. Descriptive statistics comparing terminology use across the three data source types during the time period 2009-2013 (see Figure 2) show that $64.00 \%$ of support group websites referred to people with disabilities using person-first language compared to $25.80 \%$ of journal articles and $15.60 \%$ of family medical center websites.

\subsection{Inferential Statistics}

Target noun phrases in journal articles about prostate cancer, celiac disease, and depression were all statistically significantly more likely to be coded as "person-first" relative to "patient" than articles about Parkinson's disease. Target noun phrases for healthcare journal articles published in 1994-1998, 1999-2003, and 2004-2008 were all statistically significantly less likely to be coded as "person-first" relative to "patient" than articles published in 2009-2013. There was no statistically significant interaction between time period and medical condition. Target noun phrases for healthcare journal articles and family medical center websites were both statistically significantly less likely to be coded as "person-first" relative to "non-person-first" than support group websites. Statistical details are provided in Table 2 and Table 3.

Table 1. Assessment of patterns in terminology use in healthcare journals-detail.

\begin{tabular}{|c|c|c|c|c|c|}
\hline \multirow{2}{*}{ Disability } & \multirow[b]{2}{*}{ Time period } & \multirow[b]{2}{*}{$\mathrm{N}$} & \multicolumn{3}{|c|}{ Outcome } \\
\hline & & & Person-first & Non-person-first (patient) & Non-person-first (other) \\
\hline \multirow[t]{5}{*}{ Prostate cancer } & 1994-1998 & 500 & $10.40 \%$ & $83.60 \%$ & $6.00 \%$ \\
\hline & 1999-2003 & 500 & $20.80 \%$ & $73.60 \%$ & $5.60 \%$ \\
\hline & 2004-2008 & 500 & $27.40 \%$ & $64.20 \%$ & $8.40 \%$ \\
\hline & 2009-2013 & 500 & $30.00 \%$ & $62.40 \%$ & $7.60 \%$ \\
\hline & Total & 2000 & $22.20 \%$ & $71.00 \%$ & $6.90 \%$ \\
\hline \multirow[t]{5}{*}{ Celiac disease } & 1994-1998 & 500 & $13.20 \%$ & $75.20 \%$ & $11.60 \%$ \\
\hline & 1999-2003 & 500 & $14.00 \%$ & $74.60 \%$ & $11.40 \%$ \\
\hline & 2004-2008 & 500 & $17.20 \%$ & $73.80 \%$ & $9.00 \%$ \\
\hline & 2009-2013 & 500 & $22.20 \%$ & $68.00 \%$ & $9.80 \%$ \\
\hline & Total & 2000 & $16.70 \%$ & $72.90 \%$ & $10.50 \%$ \\
\hline \multirow[t]{5}{*}{ Depression } & 1994-1998 & 500 & $27.80 \%$ & $54.40 \%$ & $17.80 \%$ \\
\hline & 1999-2003 & 500 & $25.00 \%$ & $54.20 \%$ & $20.80 \%$ \\
\hline & 2004-2008 & 500 & $33.00 \%$ & $49.20 \%$ & $17.80 \%$ \\
\hline & 2009-2013 & 500 & $36.80 \%$ & $42.60 \%$ & $20.60 \%$ \\
\hline & Total & 2000 & $30.70 \%$ & $50.10 \%$ & $19.30 \%$ \\
\hline \multirow[t]{5}{*}{ Parkinson's disease } & 1994-1998 & 500 & $2.60 \%$ & $85.40 \%$ & $12.00 \%$ \\
\hline & 1999-2003 & 500 & $6.60 \%$ & $83.40 \%$ & $10.00 \%$ \\
\hline & 2004-2008 & 500 & $11.60 \%$ & $77.00 \%$ & $11.40 \%$ \\
\hline & 2009-2013 & 500 & $14.00 \%$ & $73.80 \%$ & $12.20 \%$ \\
\hline & Total & 2000 & $8.70 \%$ & $79.90 \%$ & $11.40 \%$ \\
\hline \multirow[t]{5}{*}{ Total } & 1994-1998 & 500 & $13.50 \%$ & $74.70 \%$ & $11.90 \%$ \\
\hline & 1999-2003 & 500 & $16.60 \%$ & $71.50 \%$ & $12.00 \%$ \\
\hline & 2004-2008 & 500 & $22.30 \%$ & $66.10 \%$ & $11.70 \%$ \\
\hline & 2009-2013 & 500 & $25.80 \%$ & $61.70 \%$ & $12.60 \%$ \\
\hline & Total & 2000 & $19.50 \%$ & $68.50 \%$ & $12.00 \%$ \\
\hline
\end{tabular}




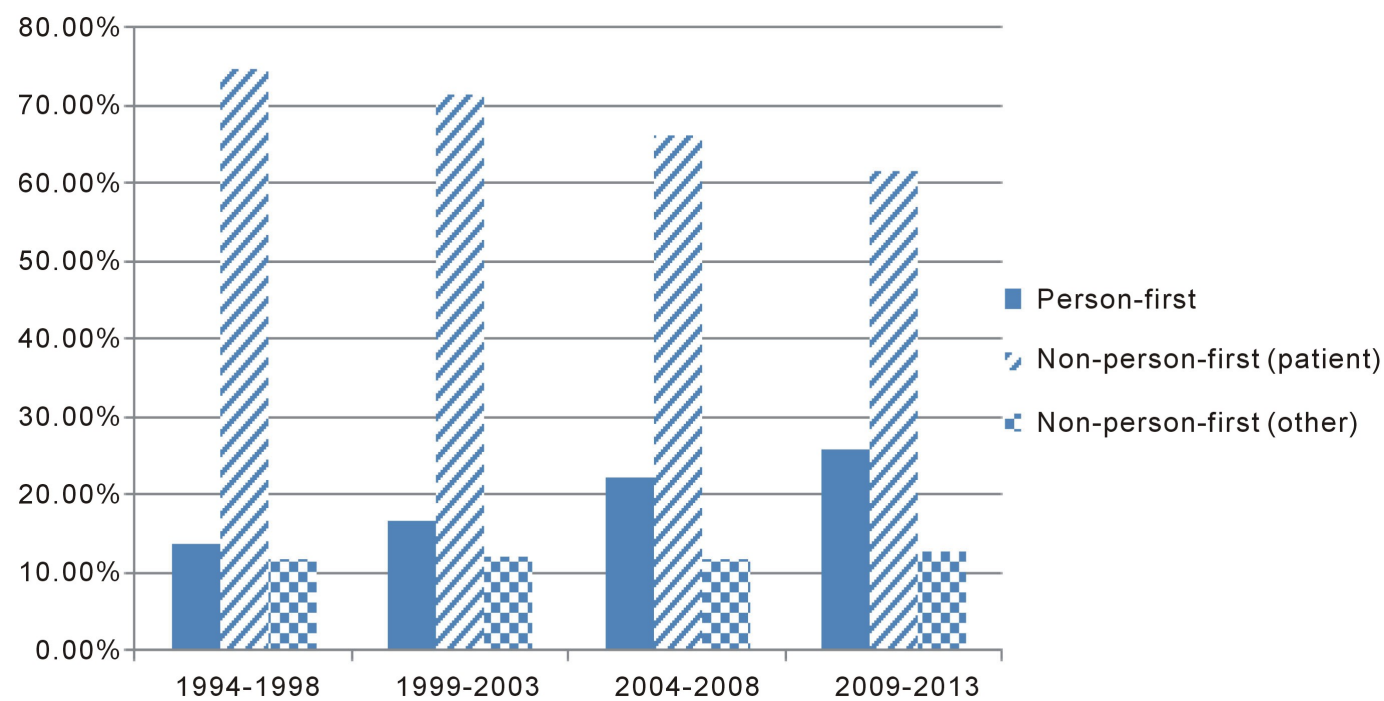

Figure 1. Assessment of patterns in terminology use in healthcare journals-overview.

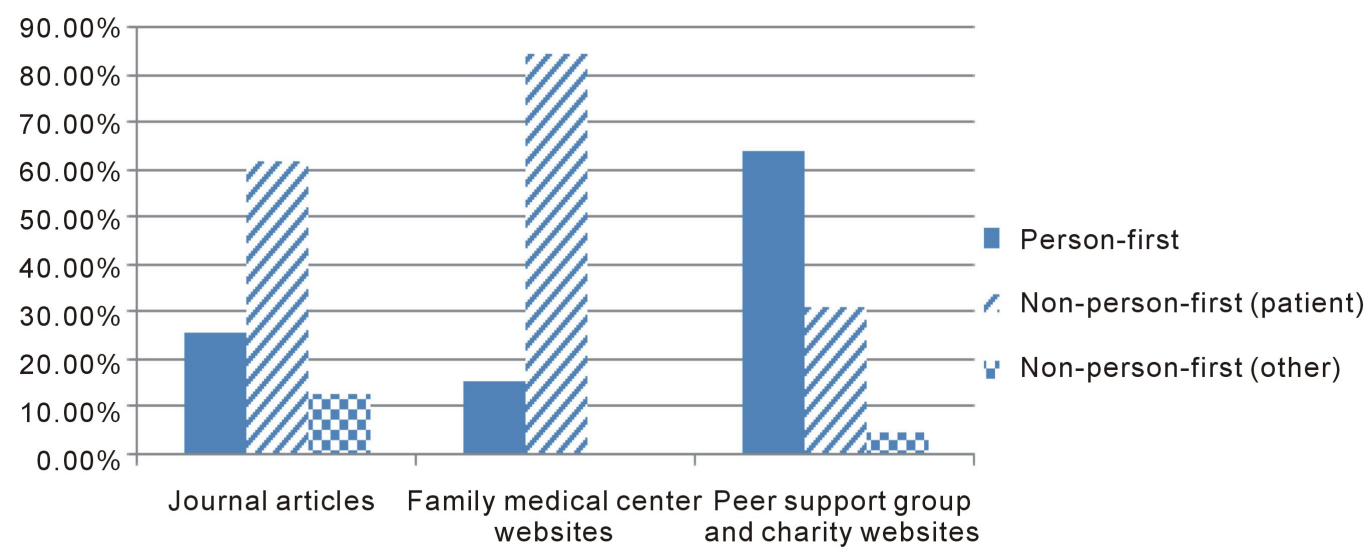

Figure 2. Comparison of terminology use across data source types during the time period 2009-2013.

\section{Discussion}

The results of the current investigation provide evidence that use of person-first language to refer to people with disabilities is becoming more prevalent in the published healthcare research literature, but remind us that it remains a minority practice. It remains unknown whether this increase is predominantly as a result of changing concepts among healthcare researchers or whether it is mainly the consequence of editorial policies by journals. The current investigation also provides first-time evidence that groups of people with disabilities tend to refer to themselves using person-first language significantly more frequently than healthcare researchers or providers use such terms to refer to people with disabilities; a phenomenon that does not appear to have been investigated in the extent published literature.

In contrast to previous quantitative characterizations of the use of person-first language in healthcare research journal articles (Patterson, 1988; La Forge, 1991; Boland, 1980), the current investigation included articles from a wide range of journals across four different medical specialties over a twenty-year period. It also analyzed a clearly defined target noun phrase as the unit of analysis and clearly stated quantitative content analysis as the underlying methodological approach. Previous studies either assessed titles, which seldom describe study participants or assessed the entire article excluding direct quotations, an approach which appears to lack focus and includes discussion of extant literature and theoretical frameworks as well as the investigation reported in the article. Moreover, previous studies did not provide detailed coding procedures or information on how conflicting 
Table 2. Inferential statistics for assessment of patterns of terminology use in healthcare journals.

\begin{tabular}{|c|c|c|c|c|c|c|}
\hline \multirow{2}{*}{ Outcome } & & \multicolumn{5}{|c|}{ 95\% confidence intervals } \\
\hline & & Coefficient & $\mathrm{p}$ & Odds ratio & Lower & Upper \\
\hline \multirow[t]{7}{*}{ Person-first } & Condition $^{*}$ Time & -0.01 & 0.69 & 0.99 & 0.94 & 1.04 \\
\hline & Prostate cancer & 0.98 & $<0.001^{* * *}$ & 2.67 & 1.68 & 4.24 \\
\hline & Celiac disease & 0.69 & $<0.001^{* * *}$ & 2.00 & 1.41 & 2.82 \\
\hline & Depression & 1.72 & $<0.001^{* * *}$ & 5.60 & 4.42 & 7.11 \\
\hline & 1994-1998 & -0.96 & $<0.001^{* * *}$ & 0.39 & 0.26 & 0.57 \\
\hline & 1999-2003 & -0.67 & $<0.001^{* * *}$ & 0.51 & 0.38 & 0.68 \\
\hline & 2004-2008 & -0.25 & $0.01^{*}$ & 0.78 & 0.64 & 0.94 \\
\hline \multirow[t]{7}{*}{ Non-person-first (other) } & Condition ${ }^{*}$ Time & -0.02 & 0.62 & 0.99 & 0.93 & 1.05 \\
\hline & Prostate cancer & -0.50 & 0.06 & 0.61 & 0.36 & 1.02 \\
\hline & Celiac disease & -0.07 & 0.70 & 0.93 & 0.64 & 1.35 \\
\hline & Depression & 0.96 & $<0.001^{* * *}$ & 2.61 & 2.05 & 3.32 \\
\hline & 1994-1998 & -0.40 & 0.14 & 0.67 & 0.39 & 1.14 \\
\hline & 1999-2003 & -0.30 & 0.12 & 0.74 & 0.50 & 1.09 \\
\hline & 2004-2008 & -0.19 & 0.14 & 0.82 & 0.64 & 1.06 \\
\hline
\end{tabular}

"Patient", "Parkinson's disease” and “2009-2013” served as reference categories, ${ }^{*}=p<0.05,{ }^{* * *}=p<0.01,{ }^{* * *}=p<0.001$.

Table 3. Inferential statistics for comparison of terminology use across data source types during the time period 2009-2013.

\begin{tabular}{ccccccc}
\multirow{2}{*}{ Outcome } & \multicolumn{1}{c}{} & & \multicolumn{2}{c}{ 95\% confidence intervals } \\
\cline { 2 - 6 } & Data source & Coefficient & $p$ & Odds ratio & Lower & Upper \\
\hline \multirow{2}{*}{ Person-first } & Journal articles & -1.63 & $<0.001^{* * *}$ & 0.20 & 0.16 \\
& Family medical center websites & -2.26 & $<0.001^{* * *}$ & 0.10 & 0.08 \\
\hline
\end{tabular}

"Non person-first”, and "peer support group and charity websites” served as reference categories, ${ }^{*}=p<0.05,{ }^{* *}=p<0.01,{ }^{* * *}=p<0.001$.

data within an article were handled. Insufficient methodological detail was included in the reports of previous studies to enable to reader to determine whether policy papers and reviews were included in the analysis or whether solely original research articles were included, as in the current investigation. Therefore, there is no high quality existing research to which the results of the current investigation can be compared and the comparisons presented should be interpreted with caution. In total, 19.50\% of healthcare research articles included in the current investigation were assessed as using person-first language. This is lower than previous investigations, which have provided figures ranging from 27\% (Patterson, 1988) to 71\% (La Forge, 1991). It is likely that the widespread differences between studies are a consequence of differences in units of analysis, coding procedures, and the scope of the samples investigated. Unlike the current investigation, previous studies were limited to rehabilitation journals, which may limit generalizability to a wider field of healthcare research given that the current investigation found significant differences between the prevalence of person-first language in different specialties. Moreover, they were unable to provide an account of changing patterns of use over time since the longest time period of analysis was one year, compared to twenty years in the current investigation.

Despite increases in the use of person-first language in healthcare research articles, there appears to be an enduring disparity between terms of reference used by people with disabilities themselves and those used by healthcare researchers and providers. This disparity is particularly striking when we note that in the current investigation, during the time period 2009-2013, 84.40\% of family medical center websites referred to people with disabilities as "patients" compared to only $31.20 \%$ of support group websites. However, we do not know how people with disabilities feel about this disparity in terminology use or whether people without disabilities who attend healthcare services for routine health checks object to being called "patients", a term of reference that may be taken to imply that they are sick or suffering (Hadley \& Brodwin, 1988; Ayto, 2001). There is scope for future qualitative research to investigate these perspectives as well as for further high quality quantitative studies to characterize changing patterns of person-first language use in healthcare research and the disparity between 
terminology used by healthcare researchers and providers and that used by people with disabilities themselves. Of particular value would be work investigating changes over time across all three data source types. This knowledge would enable us to assess whether terminology used may be impacting upon shared decision-making in healthcare practice and alienating potential research participants.

\section{Acknowledgements}

Dr Barnish acknowledges all those who have inspired him so far on his journey as an academic and writer. He has no conflicts of interest to declare relevant to this work.

\section{References}

Abdi, H. (2007) The Bonferonni and Šidák Corrections for Multiple Comparisons. In N. J. Salkind (Ed.), Bureau Measurement and Statistics. Thousand Oaks, CA: Sage. http://www.utdallas.edu/ herve/Abdi-Bonferroni2007-pretty.pdf

Allen, J., Gay, B., Crebolder, H., Heyrman, J., Svab, I., et al. (2002). The European Definitions of the Key Features of the Discipline of General Practice: The Role of the GP and Core Competencies. British Journal of General Practice, 52, 526-527.

American Speech-Language-Hearing Association (Undated). American Speech-Language-Hearing Association Resource on Person-First Language. http://www.asha.org/publications/journals/submissions/person_first/

Ayto, J. (2001). Bloomsbury Dictionary of Word Origins. London: Bloomsbury.

Blaska, J. (1993). The Power of Language: Speak and Write using “Person First”. Perspectives on Disability, 1993, $25-32$.

Boland, J. (1980). 1975-1980: Five Long Years or Five Short Years? Journal of Rehabilitation, 46, 40-41

Charles, C., Gafni, A, \& Whelan, T. (1997). Shared Decision-Making in the Medical Encounter: What Does It Mean? (Or it Takes at Least Two to Tango). Social Science and Medicine, 44, 681-692.

Crystal, D. (1985). A Dictionary of Linguistics and Phonetics. Oxford: Basil Blackwell.

Field, A.P. (2006). Discovering Statistics Using SPSS (and Sex, Drugs and Rock'n'roll). London: Sage.

Go, M.J. (1984). Quantitative Content Analysis. In W.B. Gudykunst, \& Y.Y. Kim (Eds.), Methods for Intercultural Communication Research (pp. 147-154). London: Sage.

Greene, W. H. (2011). Econometric Analysis. Harrow: Pearson Education.

Hadley, R. G., \& Brodwin, M. G. (1988). Language about People with Disabilities. Journal of Counseling and Development, 67, 147-149. http://dx.doi.org/10.1002/j.1556-6676.1988.tb02079.x

La Forge, J. (1991). Preferred Language Practice in Professional Rehabilitation Journals. Journal of Rehabilitation, 57, 4951.

National Library of Medicine (1996). http://www.ncbi.nlm.nih.gov/pubmed

National Institute for Clinical Excellence. (2009). Depression in Adults: The Treatment and Management of Depression in Adults. http://www.nice.org.uk/guidance/CG90

Office for Disability Issues (Undated). Language.

http://webarchive.nationalarchives.gov.uk/20130812104657/http://odi.dwp.gov.uk/inclusive-communications/representati on/language.php

Patel, S. R., \& Bakken, S. (2010). Preferences for Participation in Decision Making among Ethnically Diverse Patients with Anxiety and Depression. Community Mental Health Journal, 46, 466-473. http://dx.doi.org/10.1007/s10597-010-9323-3

Patterson, J. (1988). Disabling Language: Fact or Fiction? Journal of Applied Rehabilitation Counseling, 19, 30-32.

Research and Training Center on Independent Living (2013). Guidelines: How to Write and Report about People with Disabilities. Lawrence, KS: Research and Training.

Riffe, D., Lacy, S., \& Fico, F. G. (1998). Analyzing Media Messages: Using Quantitative Content Analysis in Research. London: Lawrence Erlbaum Associates.

Spooner, A. (Ed.) (1998). Oxford Quick Reference Thesaurus. Oxford: Oxford University Press. 
Scientific Research Publishing (SCIRP) is one of the largest Open Access journal publishers. It is currently publishing more than 200 open access, online, peer-reviewed journals covering a wide range of academic disciplines. SCIRP serves the worldwide academic communities and contributes to the progress and application of science with its publication.

Other selected journals from SCIRP are listed as below. Submit your manuscript to us via either submit@scirp.org or Online Submission Portal.
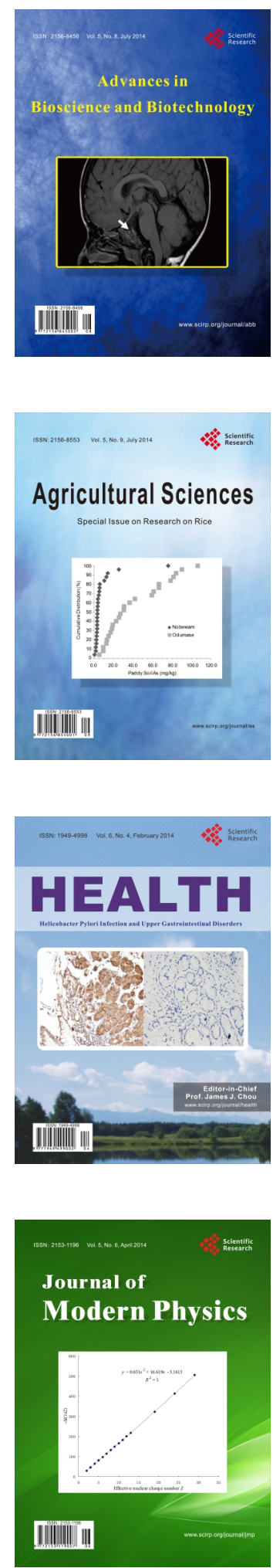
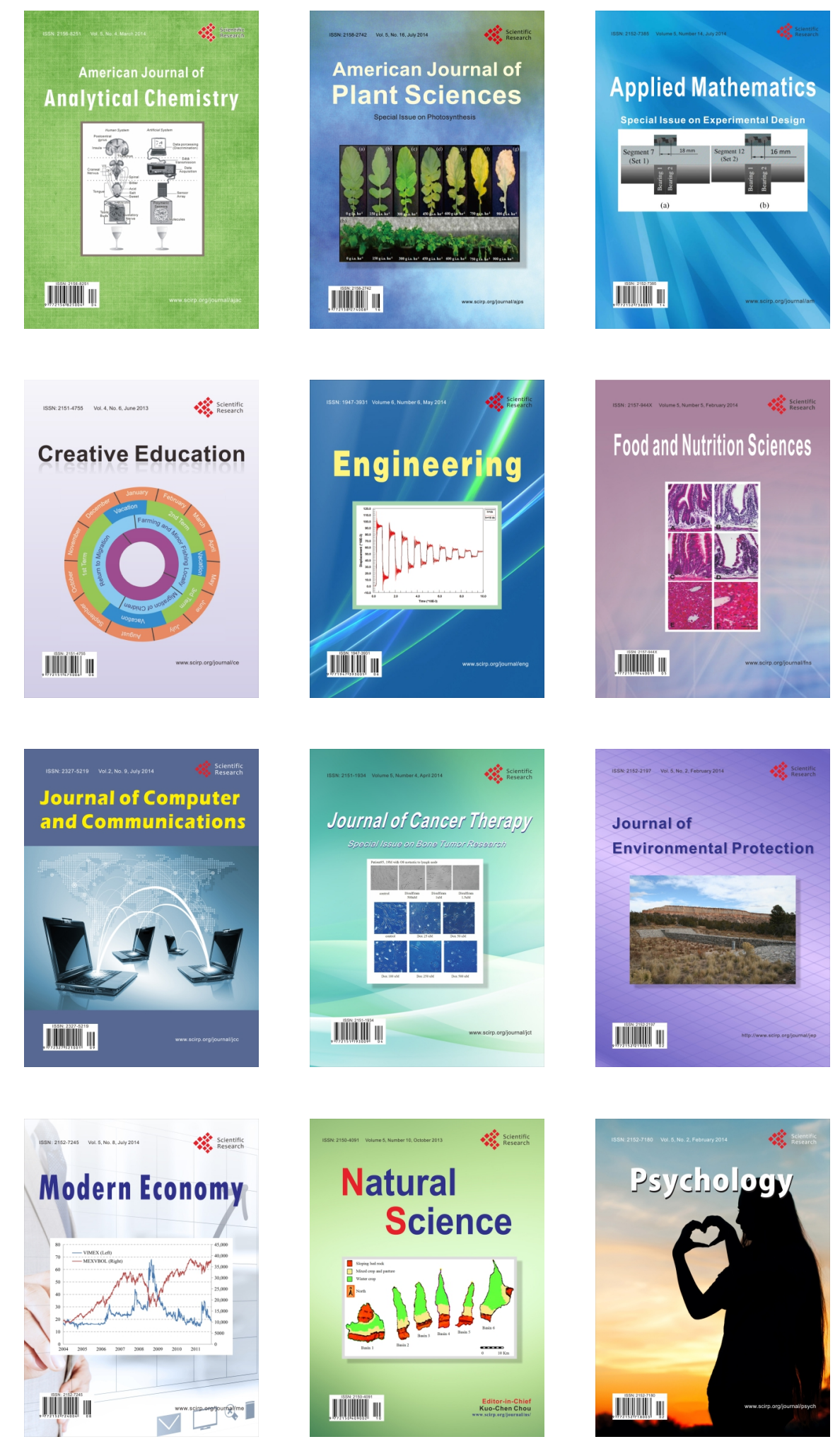